\title{
Mild temperature amination of aryl iodides and aryl bromides with aqueous ammonia in the presence of $\mathrm{CuBr}$ and pyridyldiketone ligands
}

\author{
Racha Abed Ali Abdine, ${ }^{a}$ Gracjan Kurpik,, ${ }^{b, c}$ Anna Walczak,, ${ }^{\text {b,c }}$ Sultan Abu A Aeash, ${ }^{a}$ Artur R. \\ Stefankiewicz, ${ }^{\text {b, } \mathrm{c}^{*}}$ Florian Monnier, ${ }^{\mathrm{a}, \mathrm{d}^{*}}$ Marc Taillefer ${ }^{\mathrm{a}^{*}}$ \\ a Ecole Nationale Supérieure de Chimie de Montpellier, Institut Charles Gerhardt Montpellier UMR 5253 CNRS, \\ $\mathrm{AM}_{2} \mathrm{~N}$, 8 rue de l'Ecole Normale, Montpellier 34296 Cedex 5, France. \\ ${ }^{\mathrm{b}}$ Faculty of Chemistry, Adam Mickiewicz University Umultowska 89b, 61-614 Poznan, Poland \\ ${ }^{c}$ Center for Advanced Technologies, Adam Mickiewicz University Umultowska 89c, 61-614 Poznan, Poland \\ d Institut Universitaire de France, IUF, 1 rue Descartes, 75231 Paris cedex 5, France
}

Catalytic systems based on copper and simple ligands of ambidentate pyridyldiketone type were used in direct amination of aryl iodides and bromides with aqueous ammonia in one of the mildest conditions described in the literature, with reaction temperature ranging beetween 25 and $80^{\circ} \mathrm{C}$.

The synthesis of primary aryl amines under mild conditions remained an challenging goal for synthetic chemist because of the importance of this class of compounds in fine chemicals production. ${ }^{1}$ The coupling of ammonia and aryl halides catalyzed by transition metals is a method of choice to prepare aryl amines in a selective and cost-effective manner. ${ }^{2}$ Efficient systems have been described with the assistance of palladium-based catalysts. ${ }^{3}$ These methods nevertheless suffered from several drawbacks such as the use of relatively toxic and expensive metal, along with sophisticated ligands (bulky ferrocene, electron-rich phosphines), strong bases and in some cases the use of ammonia pressure. ${ }^{3}$ In 2007 , as part of our studies in the Cu-catalysed arylation of nucleophiles, we showed that amination of aryl iodides and bromides with the use of aqueous ammonia could be performed using a copper-based catalytic system. ${ }^{4}$ Since then, a lot of related methods proceeding in the presence of various ligands have been reported in this field at temperature mainly ranging between $90{ }^{\circ} \mathrm{C}$ and $130^{\circ} \mathrm{C} .^{2}$ The use of proline ${ }^{5}$ and 2-pyridinyl- $\beta$-ketone $e^{6}$ as ligand allowed the coupling of aryl iodides with aqueous ammonia to be performed at room temperature, whereas acetylacetone permitted to proceed at $60-90{ }^{\circ} \mathrm{C}$ (Scheme $\left.1, \mathrm{X}=\mathrm{I}\right) .^{4}$ Amination of aryl iodides could also be performed at $50^{\circ} \mathrm{C}$ in the presence of $\mathrm{Cu}(\mathrm{I})$ and 2-carboxylic acidquinoline- $N$-oxide as ligand. ${ }^{7}$ There are relatively few examples reported for this transformation under mild temperature conditions (below $90{ }^{\circ} \mathrm{C}$ - Scheme $1, \mathrm{X}=\mathrm{Br}$ ) in the presence of arylbromides. ${ }^{2}$ Proline ligand was used to perform amination in good yields at 80 ${ }^{\circ} \mathrm{C}$ with $\mathrm{ArBr}$ bearing EW groups, but in poor yields with the aromatic cycle substituted by ED groups. ${ }^{5}$ The coupling of $\mathrm{ArBr}$ with aqueous ammonia at $50{ }^{\circ} \mathrm{C}$ was also reported in the presence of 4-hydroxy-L-proline ${ }^{8}$ and recently with a novel family of ligand (oxalic diamides) allowing the coupling of $\mathrm{ArBr}$ with $\mathrm{NH}_{3} \cdot \mathrm{H}_{2} \mathrm{O}$ at $80{ }^{\circ} \mathrm{C}$ with high turnovers. ${ }^{9}$ In our previous report, ${ }^{4}$ we showed that acetylacetone ligand in association with $\mathrm{Cu}(\mathrm{acac})_{2}$ was able to 
perform amination of aryl bromides at $90^{\circ} \mathrm{C}$, and at $60^{\circ} \mathrm{C}$ for activated aryl bromides bearing electron-withdrawing groups.

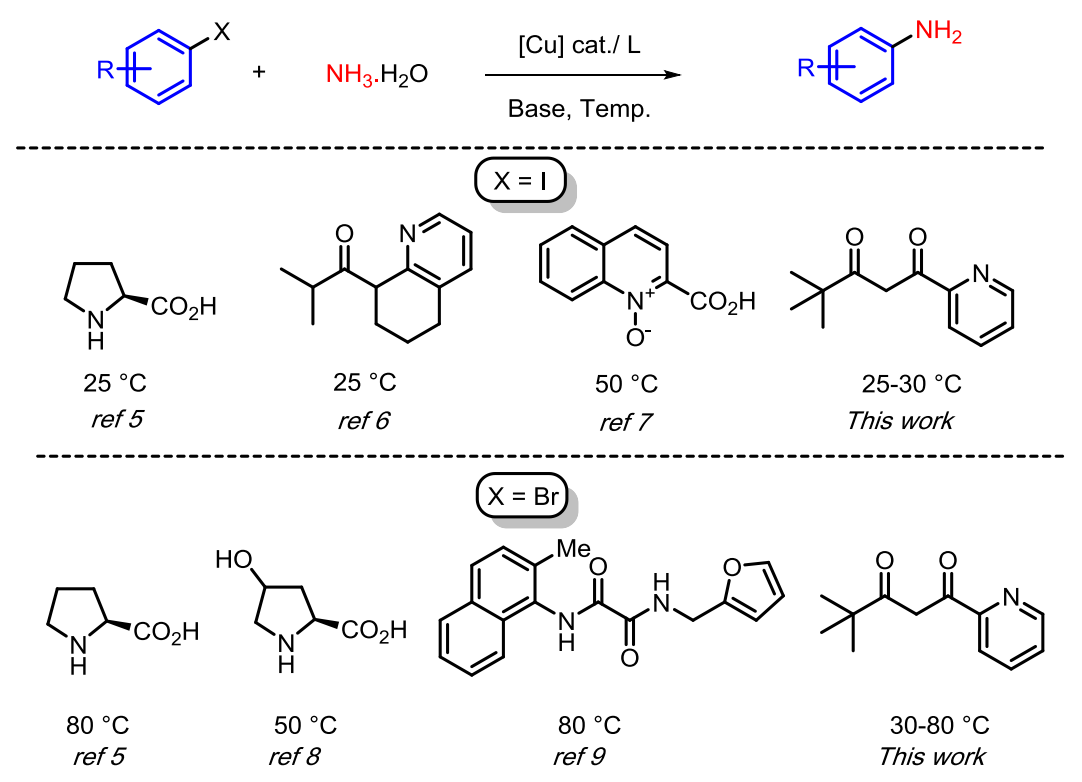

Scheme 1: Selected ligands for copper-catalyzed amination of $\mathrm{Arl}$ and $\mathrm{ArBr}$ under mild temperature conditions.

Under this context, we now report that simple ligands of ambidentate pyridyldiketone type can allow amination of aryl iodides and aryl bromides respectively at room temperature and at $30-80^{\circ} \mathrm{C}$.

Ambidentate pyridyldiketones ligands containing two distinct coordination sites of different nature (i.e. anionic $\beta$-diketonate and neutral pyridine) despite their wide use for the construction of linkage isomers, ${ }^{10}$ homo- and heteromultimetallic complexes ${ }^{11}$ and large metallosupramolecular architectures ${ }^{12}$ through coordination-driven self-assembly, have not been often employed in the Cu catalyzed arylation of nitrogen nucleophiles and never tested in the presence of aqueous ammonia. ${ }^{13}$ Thus, isomeric compounds L1-L3 (Table 1) are potential bifunctional ligands, that could be readily immobilized on a matrix of tetrahedral $\mathrm{Cu}(\mathrm{I})$ metal ion by means of acetylacetonate and pyridyl chelation. We have recently shown a first application for these ambidentate ligands, that the linkage isomers of the $\mathrm{Pd}(\mathrm{II})$ complexes of L1 and L2 are efficient catalyst precursors for the Suzuki-Miyaura reaction. ${ }^{10}$ The ligands L1 and L2 as well as previously uncharacterised L3, were prepared according to the literature procedure, ${ }^{10}$ by Claisen condensation of appropriate methyl ester with pinacolone in the presence of strong base (see supporting information for details).

A model was chosen for the reaction development study, and 4-chloro-iodobenzene 2 was engaged with 5 equivalents of $\mathrm{NH}_{3} \cdot \mathrm{H}_{2} \mathrm{O}$ using a combination of $10 \mathrm{~mol} \%$ of $\mathrm{CuBr}$ and $20 \mathrm{~mol}$ $\%$ of ambidentate pyridyldiketones $\mathbf{L 1}, \mathbf{L 2}$ or $\mathbf{L} 3$ at $30{ }^{\circ} \mathrm{C}$ (Table 1). Bases such as $\mathrm{Cs}_{2} \mathrm{CO}_{3}$ 
and $\mathrm{K}_{3} \mathrm{PO}_{4}$ were tested with various solvents including DMF or DMSO (Table 1, entries 112). The majority of reactions studied in the presence of copper bromide and ligands L1, L2 and L3 occurred in high yields at this temperature and for the following of the study we used the couple $\mathrm{DMSO} / \mathrm{K}_{3} \mathrm{PO}_{4}$ which allows whatever the ligand tested, the formation of the expected $p$-chloroaniline 2a with excellent yields (Table 1 entries 10-12). Moreover DMSO and $\mathrm{K}_{3} \mathrm{PO}_{4}$ offer the advantage of being cheaper and less toxic than DMF and $\mathrm{Cs}_{2} \mathrm{CO}_{3}$. Noteworthy that decreasing reaction temperature to $25{ }^{\circ} \mathrm{C}$ slightly lowers the yield of $2 \mathrm{a}$ (below this temperature the yields are very low).

We then explore the scope of this system in the best developed conditions (Table 1, entry 12). Combination of catalytic amounts of ligands L1, L2 and L3 and of CuBr allows the amination of various structurally distinct aryl iodides (Scheme 2).

Table 1: Amination of 4-chloroiodobenzene 2 using ligands L1, L2, L3. ${ }^{a}$

\begin{tabular}{|c|c|c|c|c|}
\hline$\overbrace{2}^{11}$ & $\begin{array}{r}+\quad \mathrm{NH}_{3} \cdot \mathrm{H}_{2} \mathrm{O} \\
5 \text { equiv. }\end{array}$ & \multicolumn{2}{|c|}{$\begin{array}{l}\text { Base, solvent } \\
25-30^{\circ} \mathrm{C}, 24 \mathrm{~h}\end{array}$} & $\mathrm{NH}_{2}$ \\
\hline igands & & & & \\
\hline entry & Ligand & Base & Solvent & Yield $^{b}$ \\
\hline 1 & L1 & $\mathrm{Cs}_{2} \mathrm{CO}_{3}$ & DMF & 65 \\
\hline 2 & L2 & $\mathrm{Cs}_{2} \mathrm{CO}_{3}$ & DMF & 66 \\
\hline 3 & L3 & $\mathrm{Cs}_{2} \mathrm{CO}_{3}$ & DMF & 64 \\
\hline 4 & L1 & $\mathrm{Cs}_{2} \mathrm{CO}_{3}$ & DMSO & 68 \\
\hline 5 & L2 & $\mathrm{Cs}_{2} \mathrm{CO}_{3}$ & DMSO & 75 \\
\hline 6 & L3 & $\mathrm{Cs}_{2} \mathrm{CO}_{3}$ & DMSO & 75 \\
\hline 7 & L1 & $\mathrm{K}_{3} \mathrm{PO}_{4}$ & DMF & 22 \\
\hline 8 & L2 & $\mathrm{K}_{3} \mathrm{PO}_{4}$ & DMF & 68 \\
\hline 9 & L3 & $\mathrm{K}_{3} \mathrm{PO}_{4}$ & DMF & 71 \\
\hline 10 & L1 & $\mathrm{K}_{3} \mathrm{PO}_{4}$ & DMSO & 84 \\
\hline 11 & L2 & $\mathrm{K}_{3} \mathrm{PO}_{4}$ & DMSO & 94 \\
\hline 12 & L3 & $\mathrm{K}_{3} \mathrm{PO}_{4}$ & DMSO & $95(87)^{c}$ \\
\hline
\end{tabular}

${ }^{a}$ Reaction conditions: 2 (0.5 mmol), $\mathrm{NH}_{3} \cdot \mathrm{H}_{2} \mathrm{O}(2.5 \mathrm{mmol})$, base $(1.25$ $\mathrm{mmol}$ ), $10 \% \mathrm{~mol} \mathrm{CuBr}, 20 \% \mathrm{~mol}$ ligand were placed in a screw tube under argon in solvent for $24 \mathrm{~h}$ at $30{ }^{\circ} \mathrm{C}$. ${ }^{b} \mathrm{NMR}$ yields using $1,3,5-$ 
trimethoxybenzene as internal standard. ${ }^{c}$ Reaction performed at $25^{\circ} \mathrm{C}$.

Aniline 1a was obtained in excellent yields whatever the ligand used (respectively 96\%, 93\% and $85 \%$ with ligands L1, L2 and L3). In many other cases, reactions in the presence of $\mathrm{CuBr}$ and ligand L3 appeared to be the highest yielding with a large scope of substrates bearing electrodonating (ED) or electrowithdrawing (EW) groups. For instance, 4chloroaniline 2a, 4-cyanoaniline 4a, 4- and 3-tolylaniline 5a and 6a, 4-fluoroaniline 9a, 3trifluoromethylaniline 10a and 4-aminoacetophenone 11a were obtained in good to excellent yields in the presence of this ligand. However, some limitations were observed when hindered 2-methyliodobenzene 7 and 4-iodophenol 12 were engaged.

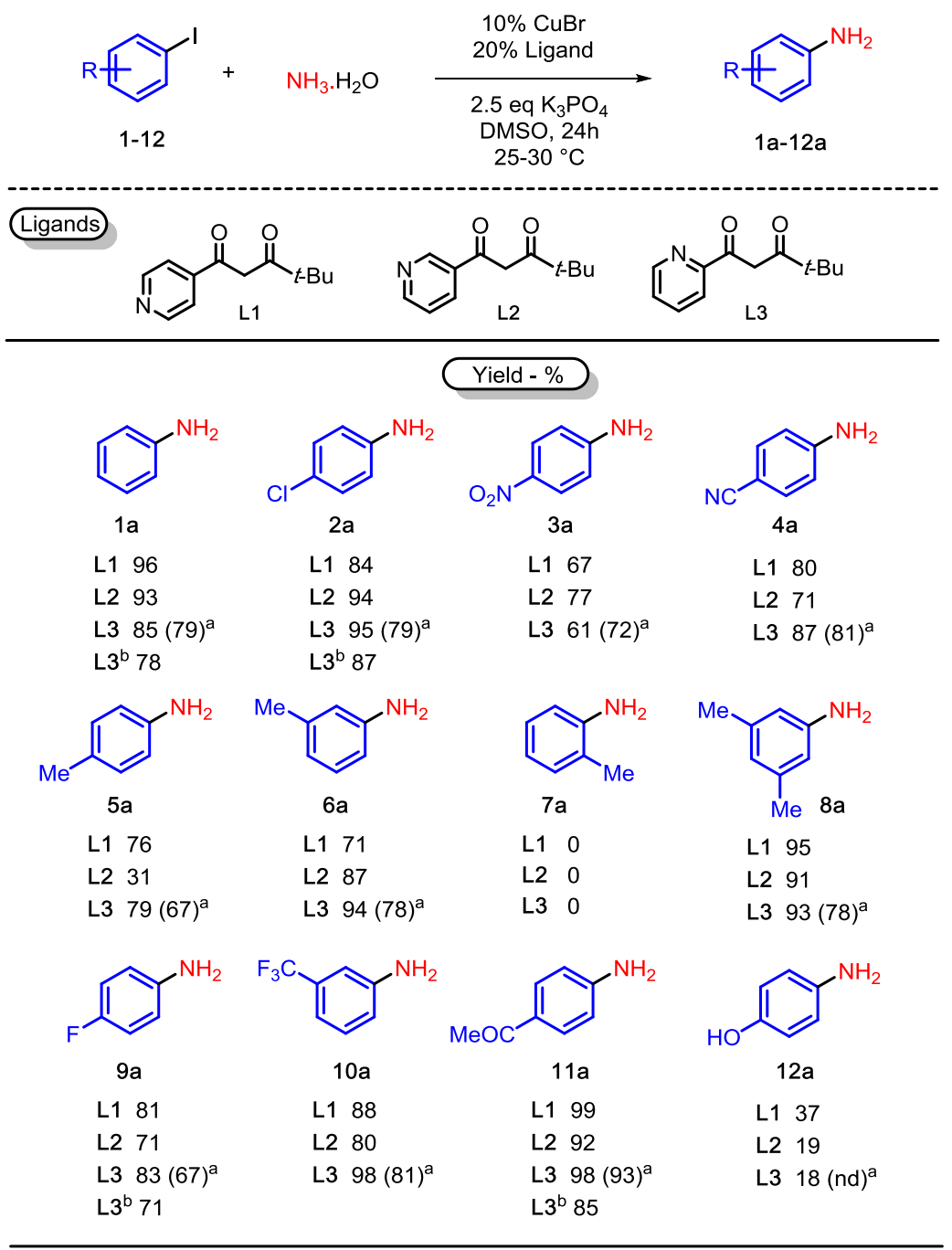

Scheme 2: Copper-catalyzed amination of $\mathrm{Arl}$ at $30{ }^{\circ} \mathrm{C}$. ${ }^{a}$ Isolated yields. ${ }^{b}$ Reaction performed at $25^{\circ} \mathrm{C}$.

It may be noted that some tests with $\mathbf{L} 3$ conducted at $25^{\circ} \mathrm{C}$ gave good but lower yields for 1a, 2a, 9a and 11a (ranging between 71 and $87 \%$ yields - Scheme 2), this reaction temperature constituting the limit below which the yields the yields are very low. 
In a second part of this study we focused our attention on arylation of aqueous ammonia with more challenging aryl bromides. The latter are less reactive electrophiles but are more attractive in terms of availability and prize compared to their iodides homologs. To further this study, we tested the activity of ligands L1, L2 and L3 under different conditions. After optimization we observed that $15 \mathrm{~mol} \%$ of $\mathrm{CuBr}$ and $30 \mathrm{~mol} \%$ of $\mathbf{L} 3$ represented the best combination to reach the best yield for $1 \mathrm{a}$ at $80^{\circ} \mathrm{C}$. These conditions were kept to perform reaction with different aryl bromides (Scheme 3). Aryl bromides bearing electron-withdrawing groups afforded the corresponding anilines in high yields at $80^{\circ} \mathrm{C}(\mathbf{4 a}, \mathbf{1 4 a}, \mathbf{1 5 a}, \mathbf{1 7 a})$ and with lower yields at $30-40^{\circ} \mathrm{C}$ (up to $62 \%-4 \mathbf{a}, \mathbf{1 7 a}$ ). Aryl bromides substituted by donor groups gave the corresponding aminated product $(\mathbf{5 a}, \mathbf{1 3} \mathbf{a}, \mathbf{1 8 a})$ in moderate to poor yields (respectively in $46 \%, 16 \%$ and $50 \%$ ). It should be noted that whatever the reaction conditions tested with aryl bromides (copper loading, $\mathrm{Cu} /$ Ligand ratio, reaction temperature) the ligand L3 was much more efficient than L1 and L2 (see Scheme 3 and Table S1 in supporting information). That was not the case from aryl iodides for which only a slightly higher efficiency was observed with L3.
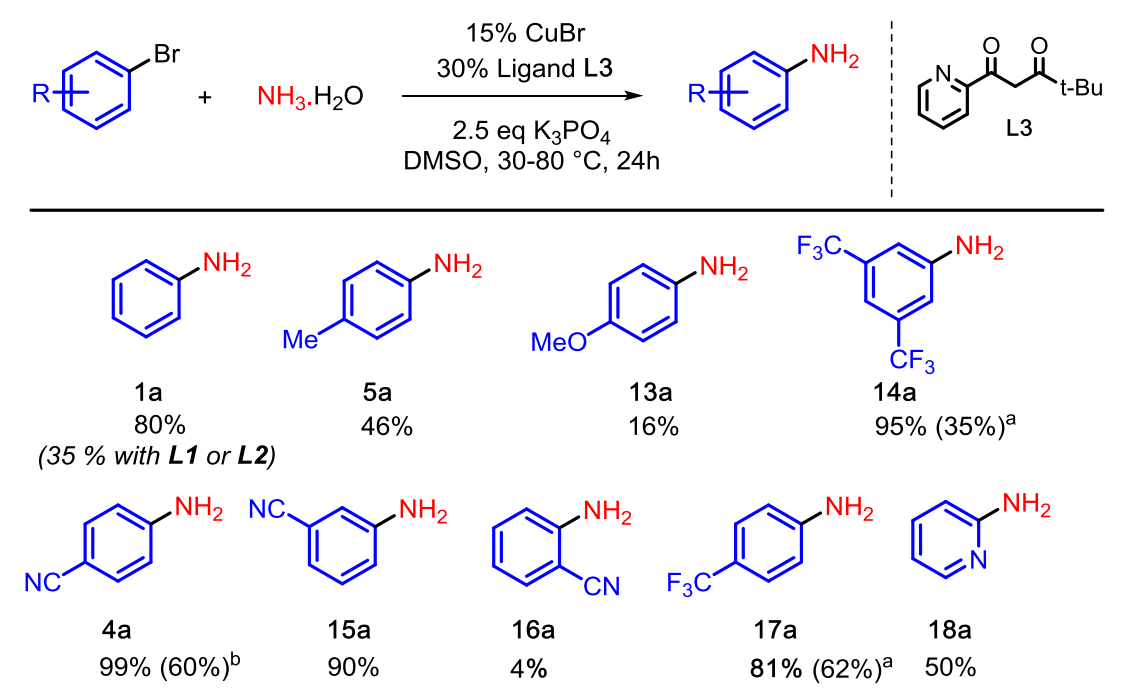

Scheme 3: Copper-catalyzed amination of $\mathrm{ArBr}$ at $80^{\circ} \mathrm{C}$. ${ }^{a}$ At $30{ }^{\circ} \mathrm{C} .{ }^{b}$ At $40{ }^{\circ} \mathrm{C}$.

A mechanism involving the generation of an anionic copper $(\mathrm{I})$ by reaction of an in situ formed $\mathrm{Cu}^{\prime}$ (pyridyldiketone) complex with the $\mathrm{N}$-nucleophile in the presence of a base could be proposed. ${ }^{14}$ The reaction of the latter with the aromatic halide would lead to a new copper (III) species (ligand)Cu'II( $\mathrm{Ar}$ )-Nu, from which the cross-coupling product would be formed via reductive elimination. The positive effect of ligand L1-L3 might be linked to the presence of two distinct donor sites (i.e. anionic $\beta$-diketonate and neutral pyridine). The higher efficiency of ligand L3, particularly illustrated in the case of reactions performed with aryl bromides, 
could be connected to a possible simultaneous chelation of its two donor sites on the same metallic center.

In conclusion, we have developed a catalytic system based on copper and a set of ambidentate pyridyldiketone ligands for amination of aryl iodides and bromides with aqueous ammonia. The accessibility of the pyridyldiketones make this method easy to perform in one of the mildest temperature conditions described in the literature. At this stage it is difficult to understand the relationship between the structure of the ligand and the reactivity observed. Work is now in progress to better identify a potential correlation and to understand the mechanism.

\section{Conflicts of interest}

"There are no conflicts to declare".

\section{Acknowledgements}

Financial support was provided by CNRS and the National Science Centre in Poland (AW, grant UMO-2016/21/N/ST5/00851) and the National Centre for Research and Development (ARS, grant LIDER/024/391/L-5/13/NCBR/2014). The work was supported by grant no. POWR.03.02.00-00-I023/17 co-financed by the European Union through the European Social Fund under the Operational Program Knowledge Education Development. F.M. also acknowledges the support of IUF.

\section{Notes and references}

1 J. H. Arpe, Industrial Organic Chemistry, Wiley 2004.

2 a) J. Schranck and A. Tlili, ACS Cat., 2018, 8, 405. b) S. Bhunia, G. G. Pawar, S. V. Kumar, Y. Jiang and D. Ma, Angew. Chem. Int. Ed., 2017, 56, 16136. c) F. Monnier and M. Taillefer, Top. Organomet. Chem., 2013, 46, 173. d) J. L. Klinkenberg and J. F. Hartwig, Angew. Chem. Int. Ed. 2011, 50, 86.

3 a) Q. Shen and J. F. Hartwig, J. Am. Chem. Soc. 2006, 128, 10028. b) D. Surry and S. L. Buchwald, J .Am. Chem. Soc. 2007, 129, 10354. c) T. Schulz, C. Torborg, S. Enthaler, B. Schäffer, A. Dumrath, A. Spannenberg, H. Neumann, A. Börner and M. Beller, Chem. Eur. J., 2009, 15, 4528.

4 a) N. Xia and M. Taillefer Fr 200706827 and PCT 2008 051701. b) N. Xia and M. Taillefer, Angew. Chem. Int. Ed., 2009, 48, 337.

5 J. Kim, S. Chang, Chem. Commun., 2008, 3052.

6 D. Wang, Q. Cai, K. Ding, Adv. Synth. Cat., 2009, 351, 1722.

7 X. Zeng, W. Huang, Y. Qiu, S. Jiang, Org. Biomol. Chem., 2011, 9, 8224.

8 L. Jiang, X. Lu, H. Zhang, Y. Jiang and D. Ma, J. Org. Chem., 2009, 74, 4542. 
9 J. Gao, S. Bhunia, K. Wang, L. Gan, S. Xia and D. Ma, Org. Lett., 2017, 19, 2809.

10 A. Walczak and A. R. Stefankiewicz, Inorg. Chem., 2018, 57, 471.

11 a) K. Banerjee and K. Biradha, New J. Chem., 2016, 40, 1997. b) A. D. Burrows, M. F. Mahon, C. L. Renouf, C. Richardson, A. J. Warren and J. E. Warren, Dalton Trans., 2012, 41, 4153. c) A. Béziau, S. A. Baudron and M. W. Hosseini, Dalton Trans., 2012, 41, 7227. d) M. J. Mayoral, P. Cornago, R. M. Claramunt and M. Cano, New J. Chem., 2011, 35, 1020.

12 a) G. L. Wang, Y. J. Lin, H. Berke and G. X. Jin, Inorg. Chem., 2010, 49, 2193. b) M. Wang, V. Vajpayee, S. Shanmugaraju, Y. R. Zheng, Z. Zhao, H. Kim, P. S. Mukherjee, K. W. Chi and P. J. Stang, Inorg. Chem., 2011, 50, 1506. c) H. B. Wu and Q. M. Wang, Angew. Chem. Int. Ed. 2009, 48, 7343.

13 For the Cu-catalzed arylation of nitrogen nucleophiles in the presence ligands of pyridyldiketone type see for example: a) X. Han, Tetrahedron Lett., 2010, 51, 360. b) Z. Xi, F. Liu, Y. Zhou and W. Chen, Tetrahedron, 2008, 64, 4254.

14 G. Lefèvre, G. Franc, A. Tlili, C. Adamo, M. Taillefer, I. Ciofini and A. Jutand, Organometallics, 2012, 31, 7694. 